\title{
Hull-tether-riser dynamics of deep water tension leg platforms
}

\author{
R. Jayalekshmi ${ }^{1}$, R. Sundaravadivelu ${ }^{2} \&$ V. G. Idichandy ${ }^{2}$ \\ ${ }^{1}$ Department of Civil Engineering, NSS College of Engineering, \\ Palakkad, Kerala, India \\ ${ }^{2}$ Department of Ocean Engineering, Indian Institute of Technology, \\ Chennai, India
}

\begin{abstract}
The exploration and production of hydrocarbons from marginal fields located in isolated ultra deep-water locations is an area of active research. Among the deep-water production platforms the tension leg platform (TLP) has proven itself to be a reliable platform choice for deep-water oil and gas developments. A riser is a unique element connecting the deck with sub sea wells and is critical to safe field operations. Though investigations reported on the riser behavior due to platform motions are many, the reported literature on the effect of riser dynamics on TLP behavior is very few. In deeper waters, risers and tethers contribute significant inertia and damping due to their longer lengths, larger sizes and heavier weights. This paper investigates the effect of riser dynamics on the response characteristics of deep water TLPs using a nonlinear finite element analysis program. To account for the nonlinearities associated with waves of large steepness, a Hybrid wave force model is proposed, which is a combination of the relative velocity model of the Morison equation and the higher order terms in the FNV model developed by Faltinsen et al. (Non linear wave loads on a slender vertical cylinder. Journal of Fluid Mechanics, 289, 179-198, 1995.) Current force is also included along with the wave forces. Parametric studies have been conducted for TLPs in two water depths; $900 \mathrm{~m}$ and $1800 \mathrm{~m}$ and wave steepness $(\mathrm{H} / \mathrm{L})$ ratios of $0.025,0.05,0.075$ and 0.1 . Results are reported in the form of power spectral density functions, mean and dynamic responses. The natural periods of TLPs are also estimated and compared with published results. The tether tension is found to increase due to inclusion of risers. The surge response is found to decrease when risers are included.

Keywords: deep water, riser dynamics, tension leg platform, nonlinear finite element analysis, hybrid wave force model, Morison model, wave steepness.
\end{abstract}




\section{Introduction}

The tension leg platform (TLP) is a moored floating stable platform where buoyancy exceeds the weight. The supplementary downward force required to maintain the equilibrium of the vertical forces is provided by vertical mooring cables, which are designed to be under tension at all times. The mooring system is a set of tension legs or tendons attached to the platform and connected to a template or foundation on the sea floor. The dynamics of tethers and risers become significant with increasing water depths as the natural frequencies of these slender structures fall in the wave frequency range causing coupling effects in the hull-tether-riser system.

The results of model tests on offshore structures reported that loads on a large diameter surface piercing cylinder due to steep waves are considerably larger than those estimated by the classic analysis. In applications where the structure is sensitive to excitation at high or low frequencies, outside the range of first-order forcing, it is necessary to consider the higher order wave forces. As the TLP structure is sensitive to excitation at high or low frequencies outside the wave frequency range, it is necessary to consider higher order wave forces. To account for the nonlinearities associated with waves of large steepness, a hybrid force model is proposed in the present study. Nonlinear Analysis of Offshore Structures (NAOS), a versatile and general nonlinear dynamic FE program [9], with the Hybrid wave force model take in to account nonlinearities of the steep waves.

\section{Theoretical back ground}

Critical assessment of literature shows that studies on deep water TLPs simulating the higher order responses are limited. In general the TLP members come under the Morison regime $(\mathrm{D} / \mathrm{L}<0.2)$. Again in deep $(\geq 900 \mathrm{~m})$ and ultra deep $(1800-3000 \mathrm{~m})$ waters the TLP columns are such that $\mathrm{kR}<\pi / 10$ and $\mathrm{R}$ is of the order of wave amplitude. The non linear effects of steep waves cannot be neglected and accounted by the long wave approximation of second and third order wave forces in Faltinsen et al. [3] (FNV method) in a simplified way.

By FNV model, the force on a surface-piercing vertical cylinder is given by

$$
F_{F N V}=F^{(1)}+F^{(2)}+F^{(3)}
$$

where $F^{(l)}$ and $F^{(2)}$ are the long wave approximation of the first and second-order force components. $F^{(3)}$ is a third order force obtained from the nonlinear potential and approximated using the assumptions regarding wave length and wave amplitude.

Following the formulation in Krokstad et al. [5],

$$
F^{(I)}=2 \pi \rho R^{2} \int_{-d}^{0} u_{t}(z) d z
$$




$$
\begin{gathered}
F^{(2)}=\left.2 \pi \rho R^{2} u_{t}\right|_{Z=0} \eta^{(1)}+\pi \rho R^{2} \int_{-d}^{0} w_{u z} d z \\
F^{(3)}=\pi \rho R^{2} \eta^{(1)}\left|u_{t z} \eta^{(1)}+w u_{z}-\frac{2}{g} u_{t} w_{t}\right|_{z=0}+\left.\pi \rho\left(R^{2} / g\right) u^{2} u_{t}\right|_{z=0} \beta(d / R)
\end{gathered}
$$

Here $R$ is the radius of the cylinder (which is assumed to be circular), $d$ is the draught, $u_{t}$ and $w_{t}$ are the horizontal and vertical particle accelerations. $\eta^{(l)}$ is the linear incident wave elevation and $\beta$ is a factor given by nonlinear long wave diffraction acting locally near the free surface. For large values of $d / R, \beta=4$. In this $F^{(l)}$ is nothing but the inertia term of the Morison equation. The FNV method does not consider the relative velocity of the cylinder, which is important for compliant platforms like TLP. In deeper water depths, the drag loads significantly increase due to larger influence of the tethers and risers. The drag loads could become as large as the inertia loads coming from the wave diffraction effects on the hull. Hence a Hybrid wave force model is proposed which estimates the first order wave force by relative velocity form of Morison equation, accounting viscous effects by the drag term and second and third order forces from the FNV model.

The FNV formulation is valid for surface piercing vertical columns only. More over at the depth of submergence of pontoons, wave effects are negligible (wave motion is felt at a depth of about half the wavelength in the fluid). Hence the Hybrid model is used for estimating the wave forces on vertical column members and Morison model as such is used for the computation of wave forces on pontoons, tethers and risers. The coupled nonlinear dynamic analysis of TLPs is performed in time domain using the finite element method with a variety of elements such as three dimensional beam, spring and mass elements. The code can treat nonlinear dynamic problems in time domain based on an updated Lagrangian formulation considering both hull-tether coupling and coupling between the six degrees of freedom of the platform. The dynamic equilibrium equation is solved in the time domain using the incremental-iterative NewmarkBeta algorithm.

\section{Parametric studies}

Parametric studies have been carried out on $900 \mathrm{~m}$ and $1800 \mathrm{~m}$ TLPs with and without risers. Typical TLP platforms which are geometrically similar to those used for the 'Deep Star Theme Structure Studies [1, 4, 7, 10, 11] are selected for the study. The geometrical particulars of the TLP platforms considered for the present study are given in Table 1. The added mass and drag coefficients can be independently prescribed for each beam element in the code. However the values adopted for the present study follows those used in the Deep Star Studies. It is also verified that the adopted values conform to the API RP 2T recommendations. Cd values adopted are 0.7 for pontoons; 1.2 for columns and 1.0 for tethers. The $\mathrm{Cm}$ values taken are 2.2 for pontoons; 2.3 for columns and 2.0 for tethers. Three dimensional beam elements are used to model the 
pontoons, columns, tethers and risers. The tether and riser nodes at the seabed have pinned boundary conditions. The pretension of the tethers is input to the finite element model as axial tension at both nodes of a tether element.

The hydrodynamic analysis of TLPs with risers have been carried out under regular waves for the wave loading conditions $\mathrm{H}=7.65 \mathrm{~m}, 15.3 \mathrm{~m}, 22.94 \mathrm{~m}$ and $30.58 \mathrm{~m}$ with wave period of $\mathrm{T}=14 \mathrm{~s}(\mathrm{H} / \mathrm{L}=0.025,0.05,0.075,0.1)$. Current force with a surface velocity of $1.07 \mathrm{~m} / \mathrm{s}$ is also included along with the wave forces. The platform motions do affect the riser deflections and stresses and the reported literature in this area is vast but the effect of riser dynamics on platform behavior is hardly any and a detailed study in this area is required for deep water TLPs. Significant variation in results can be expected as water depth and number of risers increase. The natural periods of TLPs with risers are also estimated and are presented in Table 2. The importance of including risers in the response study is highlighted in Table 2. The natural periods of TLPs with riser compare well with the published results of MARINTEK (Zou et al. [11]).

The variation of spectral distribution of responses for $d=1800$ are illustrated in Figs 1, 2, 3 and 4. The effect of riser dynamics on various response measures for the two water depths are also given in Figs 5 to 8 .

Table 1: $\quad$ Platform details of the deep water TLPs under parametric study.

\begin{tabular}{|c|c|c|}
\hline Case Description & $900 \mathrm{~m}$ & $1800 \mathrm{~m}$ \\
\hline 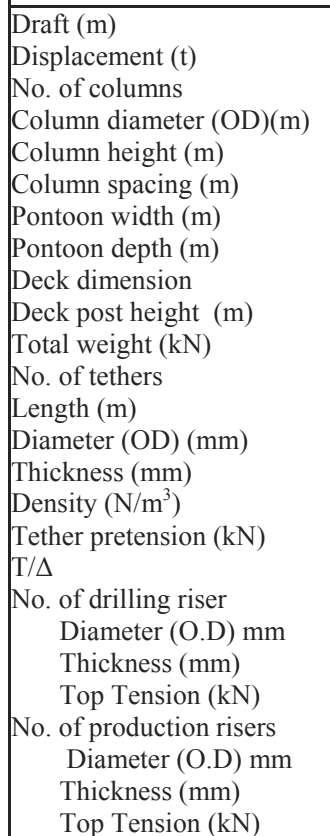 & $\begin{array}{l}24 \\
32667 \\
4 \\
16.2 \\
44.1 \\
60 \\
8.1 \\
7.2 \\
72 \mathrm{~m} \times 72 \mathrm{~m} \\
2.4 \\
240770 \\
8 \\
878.4 \\
812.8 \\
33 \\
77000 \\
71,868 \\
0.22 \\
1 \\
533.4 \\
33.4 \\
3165 \\
7 \\
279.4 \\
25.4 \\
1809\end{array}$ & \begin{tabular}{|l}
30.9 \\
52205 \\
4 \\
19.2 \\
52.5 \\
60 \\
9.6 \\
8.4 \\
$78 \mathrm{~m} \times 78 \mathrm{~m}$ \\
2.4 \\
346656 \\
12 \\
1769.1 \\
1117.6 \\
47 \\
77000 \\
114,851 \\
0.22 \\
1 \\
533.4 \\
33.4 \\
7012 \\
7 \\
279.4 \\
25.4 \\
3393
\end{tabular} \\
\hline
\end{tabular}


Table 2: $\quad$ Natural periods of TLPs (s).

\begin{tabular}{|l|l|l|l|c|l|l|}
\hline \multirow{2}{*}{ Water depth } & \multicolumn{3}{|c|}{$900 \mathrm{~m}$} & \multicolumn{3}{|c|}{$1800 \mathrm{~m}$} \\
\hline & \multirow{2}{*}{$\begin{array}{c}\text { Without } \\
\text { Riser }\end{array}$} & \multicolumn{2}{|l|}{ With riser } & Without & \multicolumn{2}{l|}{ With riser } \\
\cline { 3 - 4 } \cline { 7 - 7 } & & Present & Published* & & Present & Published* \\
\hline Surge & 117.48 & 144.5 & 144 & 174.2 & 220.8 & 225 \\
\hline Heave & 2.873 & 3.34 & 3.4 & 3.15 & 4.1 & 4.0 \\
\hline
\end{tabular}
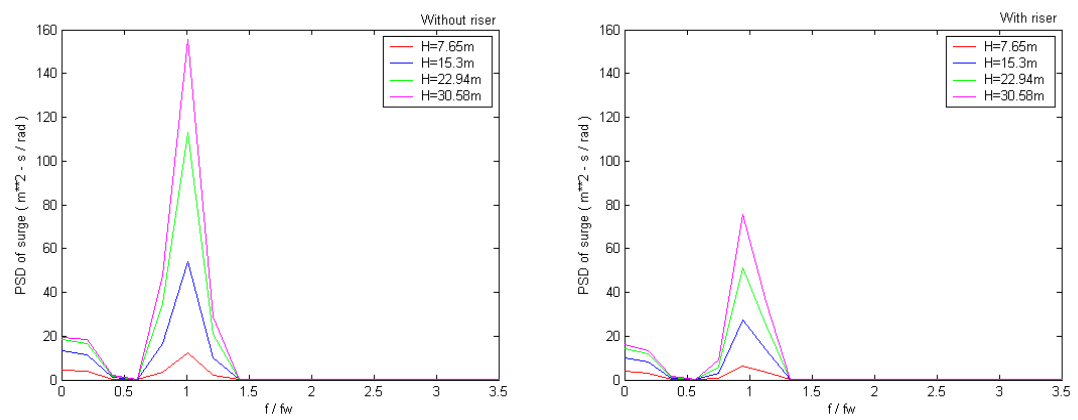

Figure 1: Comparison of spectral distribution of surge with and without risers.
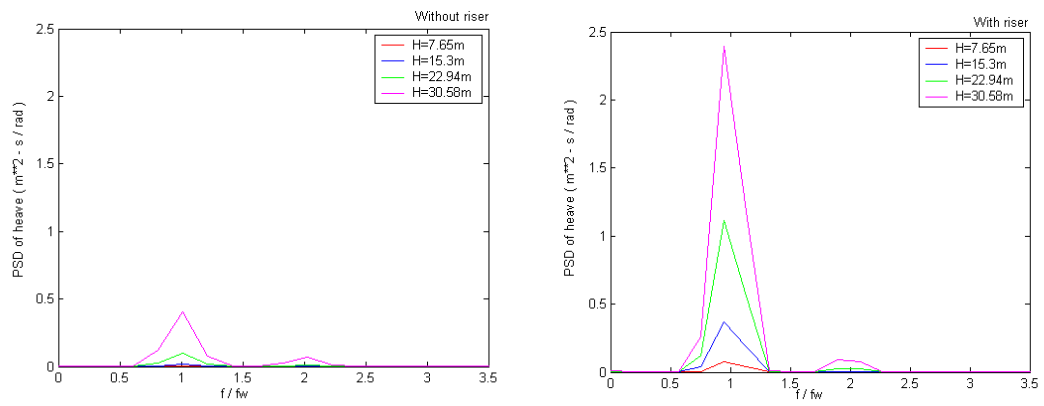

Figure 2: Comparison of spectral distribution of heave with and without risers.

The dynamic surge and maximum spectral densities are reduced to $75-85 \%$ for $\mathrm{d}=900 \mathrm{~m}$ and $55-65 \%$ for $\mathrm{d}=1800 \mathrm{~m}$ when $\mathrm{H} / \mathrm{L}$ is 0.1 . This could be due to the riser hydrodynamic damping, which is related to the riser drag. The mean drift surge increases significantly when risers are included. This could be due to the steady current drag. 

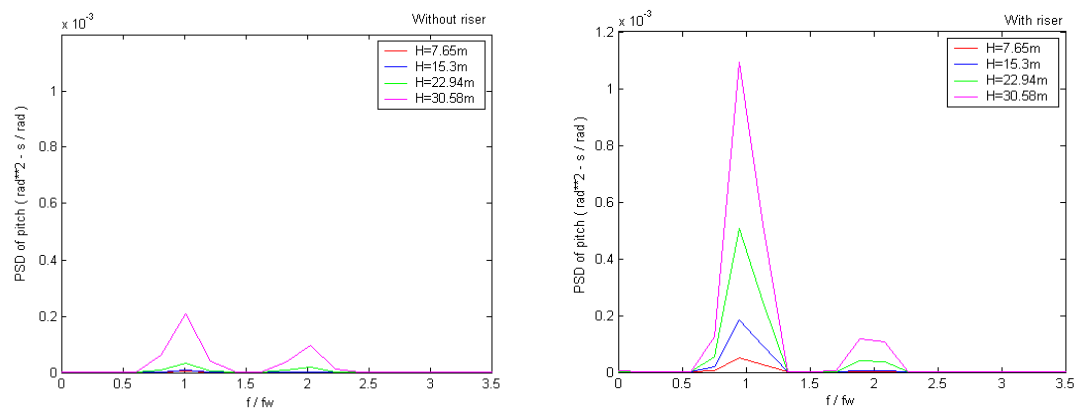

Figure 3: Comparison of spectral distribution of pitch with and without risers
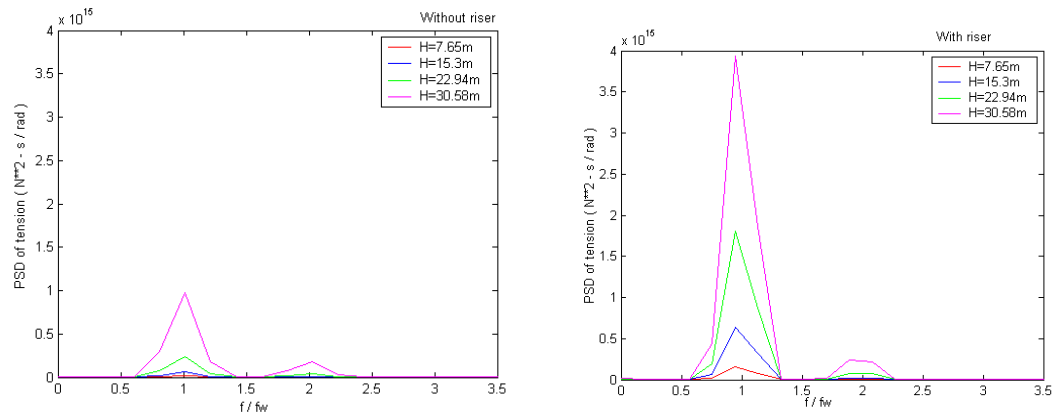

Figure 4: Comparison of spectral distribution of tether tension.
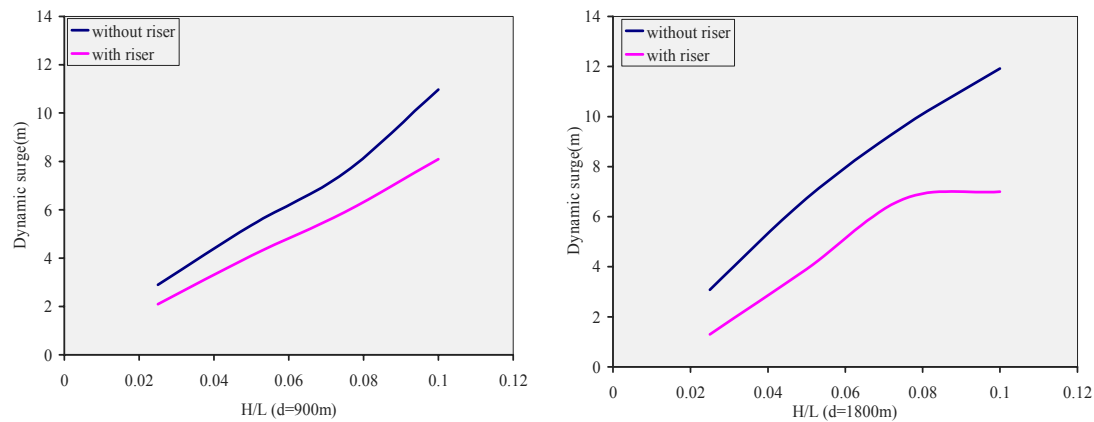

Figure 5: Comparison of dynamic surge with and without risers $(\mathrm{d}=900 \mathrm{~m}$ and $1800 \mathrm{~m})$. 

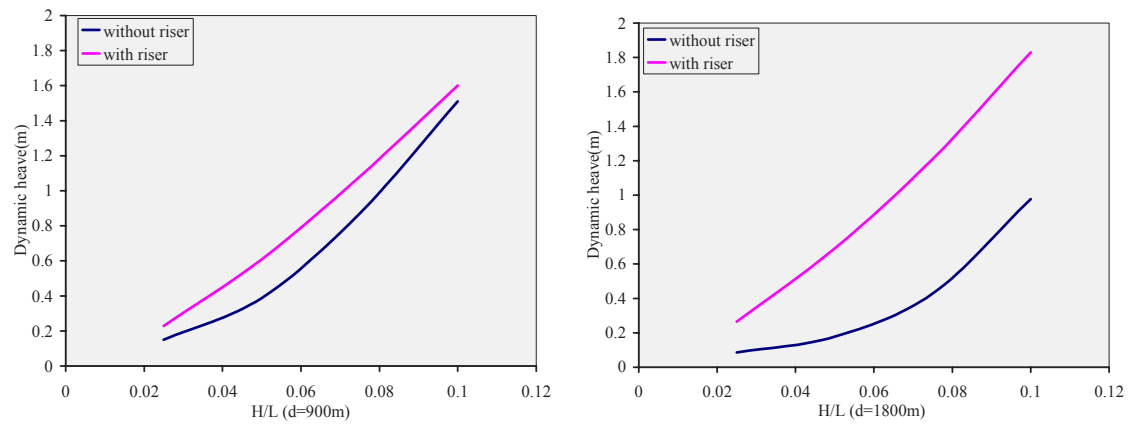

Figure 6: Comparison of dynamic heave with and without risers $(\mathrm{d}=900 \mathrm{~m}$ and $1800 \mathrm{~m})$.
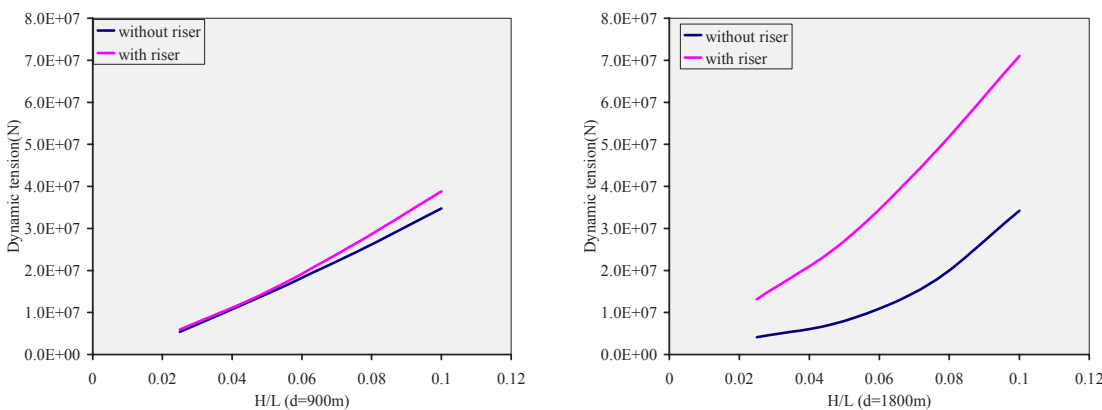

Figure 7: Comparison of dynamic tether tension with and without risers $(d=$ $900 \mathrm{~m}$ and $1800 \mathrm{~m})$.
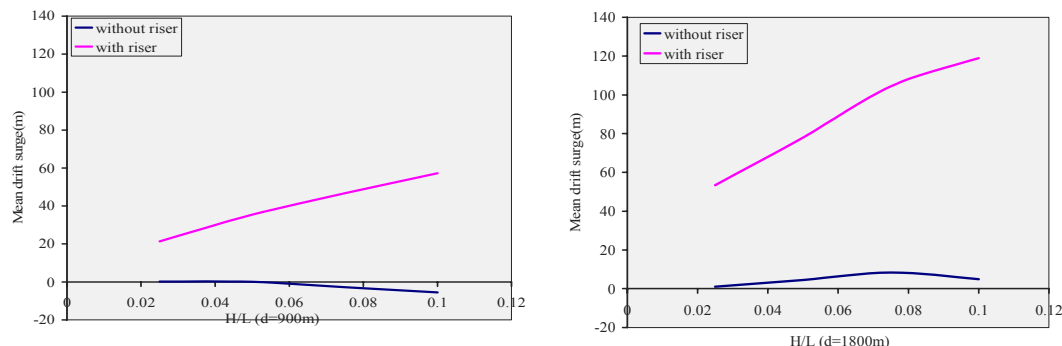

Figure 8: Comparison of mean drift surge with and without risers $(d=900 \mathrm{~m}$ and $1800 \mathrm{~m})$.

Similar to surge, the dynamic heave and set down increases with wave steepness when risers are considered. The dynamic heave is increased 1-1.5 times for $\mathrm{d}=900 \mathrm{~m}$ and 2-4 times for $\mathrm{d}=1800 \mathrm{~m}$. The PSD of heave is magnified to 5-6 times. This may be due to the excitation of heave mode with 
higher tether modes and riser modes. As the mean drift surge increases, the set down also increases. Similar variation is observed for both the water depths.

The pitch amplitude is almost doubled and maximum PSD of pitch is increased to about 4 times due to the inclusion of risers.

The effect of risers on dynamic tether tension for $900 \mathrm{~m}$ deep TLP is not significant and is magnified 2-3 times for $1800 \mathrm{~m}$ deep TLP and the PSD of tension is increased to $5-6$ times.

\section{Summary and conclusions}

An in house finite element program developed for the nonlinear analysis of offshore structures in time domain with a hybrid wave force model is used for the analysis of TLPs. TLPs are investigated for the effect of risers in regular waves in two water depths; $900 \mathrm{~m}$ and $1800 \mathrm{~m}$. Regular wave loading corresponding to wave steepness values $\mathrm{H} / \mathrm{L}=0.025,0.05,0.075$ and 0.1 are considered. The effect of risers in the Hull-Tether-Riser coupled analysis is to reduce the dynamic surge and to increase the dynamic heave and dynamic tension. The dynamic surge is reduced due to the riser hydrodynamic damping related to riser drag. Similar effect is observed for spectral density of responses also. The effect of riser is to increase the mean drift surge and set down and is due to the additional hydrodynamic forces and current forces. This increase in mean drift surge and set down increases with wave steepness for both water depths of $900 \mathrm{~m}$ and $1800 \mathrm{~m}$.

\section{References}

[1] Bhat, S.U., Greiner, W.L. and Barton, D. Deep Star 10,000-ft Water Depth Study, Proc. of Offshore Technology Conference, OTC15102, 2003.

[2] Chakrabarti, S.K. Handbook of Ocean Engineering Vol I and Vol. II, ELSEVIER Publication, 2005.

[3] Faltinsen, O.M., Newman, J.N. and Vinjie, T. Non linear wave loads on a slender vertical cylinder. Journal of Fluid Mechanics, 289, 179-198, 1995.

[4] Kim, M.H., Tahar, A. and Kim, Y.B. Variability of TLP Motion Analysis against Various Design Methodologies /Parameters, Proc. of the $11^{\text {th }}$ InterNational Offshore and Polar Engineering Conference, 467-473,2001.

[5] Krokstad, J.R., Marthinsen, T., Nestegard and Stansberg, C.T. A New NonSlender Ringing Load Approach Verified against Experiments. OMAE'96, 371-387, 1996.

[6] Marthinsen, T., Stansberg, C.T. and Krokstad, J.R. On the Ringing Excitation of Circular Cylinders, Proc. of the $6^{\text {th }}$ International Offshore and Polar Engineering Conference, 196-204, 1996.

[7] Ma, W., Lee, M.Y, Zou, J. and Huang, E.W. Deepwater nonlinear coupled analysis tool, Proc. of Offshore Technology Conference, OTC12085, 2000.

[8] Newman, J.N. The second-order wave force on a vertical cylinder, Journal of Fluid mechanics, 320, 417-443, 1996. 
[9] Sreekumar, R. Analytical and experimental investigations on the dynamics of deepwater mini tension leg platform. Ph.D. Thesis, Dept of Ocean Engineering, IIT Madras, 2001.

[10] Wichers, J. and Devlin, P.V. Benchmark Model Tests on the Deep Star Theme Structures FPSO, SPAR and TLP. Proc. of Offshore Technology Conference, OTC 16582, 2004.

[11] Zou, J., Ormberg, H. And Stansberg, C.T. Prediction of TLP Responses: Model Tests vs. Analysis, Proc. of Offshore Technology Conference, OTC 16584, 2004. 